\title{
- Occupational Hypertension among Professionals of Bijapur City: A Letter to the Editor
}

\section{IJCRR}

Section: Healthcare

ISI Impact Factor

(2019-20): 1.628

IC Value (2019): 90.81

$\operatorname{SJIF}(2020)=7.893$

\section{Debasish Kar Mahapatra}

Chief Medical Officer (Retired), Medical Department, Western Coalfields Limited (Subsidiary Company of Coal India Limited), Nagpur 4400o1, Maharashtra, India
It is a pleasure writing a Letter to the Editor for the published article: Yadavannavar MC, Patil SS, Algur V. Prevalence of hypertension in Some Occupational groups of Bijapur City. Int J Cur Res Rev. 2011;3(8):42-8.

A cross-sectional study was done for a period of one year to know the prevalence of Hypertension and the risk factors associated with it by interview technique using pre-tested proforma. Participants were all Doctors working in two Medical Colleges, High school teachers, and employees of Nationalised Banks. The authors have accepted the definition of High blood pressure or Hypertension defined by WHO as systolic pressure equal to or greater than $140 \mathrm{~mm} \mathrm{Hg} \mathrm{\&} \mathrm{/} \mathrm{or} \mathrm{diastolic}$ pressure equal to or greater than $90 \mathrm{~mm} \mathrm{Hg}$.

The present study is aimed to find out the prevalence of hypertension in some occupational groups with a sedentary lifestyle and to know the influence of various risk factors on the prevalence of hypertension in these groups. The variables studied included Age, Sex, Occupation, BMI, Diet, Physical Exercise, Alcohol, Tobacco, Higher prevalence of hypertension was found among those who had a family history of hypertension in all the three groups. The R.R of developing hypertension was 1.54 times more among those who had a family history of hypertension than those who did not have. The R.R of developing hypertension was 1.54 times more in those who were not doing physical exercise regularly those who were doing exercise regularly is a good observation. Sedentary lifestyle, unhealthy dietary habits (extra salt $\&$ fat consumption), lack of physical exercise, tobacco, \& alcohol consumption, and increased stress due to change in lifestyle because of rapid urbanization, appear to exert great influence on the prevalence of hypertension, besides, non-modifiable risk factors like age, family history, genetic factors in our study groups which are similar to the observation of other workers.

The authors have emphasized the need to create awareness among the general population to bring about changes in their lifestyle and dietary habits besides avoiding other risk factors. However, the authors should have mentioned JNC-7 and the statistical analysis has not been concluded clearly. 